\title{
Offline exhaled nitric oxide in children: chemiluminescence vs. electrochemical devices
}

\author{
Wilmer A. Madrid ${ }^{1}$, Carlos Guzmán-Valderrábano ${ }^{1,2}$, David Martínez-Briseño ${ }^{3}$, Luis Torre-Bouscoulet4, \\ David H. Ramírez-San Juan ${ }^{4}$, and Laura Gochicoa-Rangel1,4*
}

${ }^{1}$ Departamento de Fisiología Respiratoria, Instituto Nacional de Enfermedades Respiratorias Ismael Cosío Villegas; ${ }^{2}$ Departmento de Pulmonología, Pedia-Hero; ${ }^{3}$ Departmento de Epidemiología y Estadística, Instituto Nacional de Enfermedades Respiratorias Ismael Cosío Villegas; ${ }^{4}$ Laboratorio de Función Pulmonar, Instituto de Desarrollo e Innovación en Fisiología Respiratoria S de RL. Mexico City, Mexico

\begin{abstract}
Background: Exhaled nitric oxide (eNO) is a noninvasive marker of airway inflammation that has been used in children, using the "offline" technique. To the extent of our knowledge, no article reported in literature compares the concordance and correlation between the two different technologies used to measure eNO at tidal volume offline. This study aimed to report the concordance and correlation of the eNO measured "offline" at tidal volume, using chemioluminiscence (cl) vs electrochemical devices (eq). Methods: A cross-sectional, observational, and prospective study was conducted in the National Institute of Respiratory Diseases (Instituto Nacional de Enfermedades Respiratorias), Mexico City. Healthy children and those with a lung disease between 1 and 11 years of age were included. The exhaled air sample at tidal volume was obtained by attaching a mask connected to a Mylar ${ }^{\oplus}$ bag. Results: We studied 36 children. The mean \pm standard deviation (SD) age of the study population was $6 \pm 2.6$ years; $25 \%$ of the subjects included were healthy, and the rest had a lung disease. The concordance correlation coefficient between the two measuring devices was $0.98(p<0.001)$, with a mean difference of $1.46 \pm 3.5 p p b$ and $95 \%$ limits of agreement from $-5.3 \mathrm{ppb}$ to $8.3 \mathrm{ppb}$. The linear regression model equation for the estimation of eNO was $e N O_{c l}=\left(e N O_{e q} \cdot 1.0718\right)-0.1343\left(r^{2}=0.97\right)$. Conclusions: The measurement of eNO at tidal volume by the offline method can be analyzed by electrochemical devices, and the results are interchangeable with those analyzed by chemiluminescence technology.
\end{abstract}

Keywords: Nitric oxide. Preschooler. Children. Infants. Offline tidal breathing. Exhaled nitric oxide.

\section{Óxido nítrico exhalado «fuera de línea» en niños: comparación entre equipos de quimioluminiscencia y electroquímicos}

\section{Resumen}

Introducción: El óxido nítrico exhalado (eNO) es un marcador no invasivo de inflamación de la vía aérea que se ha utilizado en niños mediante técnica «fuera de línea». Por lo que sabemos, en la literatura no existen reportes que comparen la concordancia y la correlación entre dos técnicas diferentes a volumen corriente. El objetivo de este trabajo es informar la concordancia y la correlación del eNO obtenido por la técnica fuera de línea a volumen corriente en los equipos de qui-

Correspondence:

*Laura Gochicoa-Rangel

E-mail: drgochis@gmail.com
Available online: 17-09-2021

Date of reception: 29-10-2020

Date of acceptation: 8-02-2021

DOI: 10.24875/BMHIM.20000345
Bol Med Hosp Infant Mex. 2021;78(5):404-410

www.bmhim.com 1665-1146/@ 2021 Hospital Infantil de México Federico Gómez. Published by Permanyer. This is an open access article under the CC BY-NC-ND license (http://creativecommons.org/licenses/by-nc-nd/4.0/). 
mioluminiscencia (cl) y electroquímico (eq). Métodos: Se realizó un estudio transversal, observacional y prospectivo en el Instituto Nacional de Enfermedades Respiratorias, en Ciudad de México. Se incluyeron niños sanos y con enfermedad pulmonar de 1-11 años de edad. La muestra de aire exhalado se obtuvo a volumen corriente mediante una máscara con conexión a una bolsa de Mylar ${ }^{\ominus}$. Resultados: Se estudiaron 36 niños. La edad promedio con su desviación estándar de la población de estudio fue de $6 \pm 2.6$ años. El $25 \%$ de los sujetos incluidos estaban sanos y el resto tenían alguna enfermedad pulmonar. El coeficiente de correlación de concordancia entre los dos equipos fue de 0.98 ( $p<0.001)$, con una diferencia media de $1.46 \pm 3.5$ ppb y unos límites de concordancia del 95\% de -5.3 a 8.3 ppb. La ecuación del modelo de regresión lineal del eNO fue $\mathrm{eNO}_{c l}=\left(e \mathrm{NO}_{e q}{ }^{-1}, 0718\right)-0.1343\left(r^{2}=0.97\right)$. Conclusiones: La medición del eNO por el método fuera de línea a volumen corriente puede analizarse en dispositivos electroquímicos. Los resultados son intercambiables con los de quimioluminiscencia.

Palabras clave: Óxido nítrico. Preescolares. Niños. Lactantes. Respiración a volumen corriente. Óxido nítrico exhalado.

\section{Introduction}

Since the description of nitric oxide (NO) as an endothelial relaxation molecule and the demonstration of $\mathrm{NO}$ in exhaled air, the measurement of this compound has been used to determine the degree of airway eosinophilic inflammation ${ }^{1-3}$. According to different guidelines for asthma management, NO measurement is considered a tool for diagnosing and treating patients with this disease ${ }^{4-6}$. In 2005, the American Thoracic Society and the European Respiratory Society (ATS/ ERS) made recommendations for the "online" (real-time display of NO measure) and "offline" (collection of exhaled air into a bag for delayed analysis) measurements of exhaled NO. The most standardized technique is the online method, in which the individual exhales with a flow of $50 \mathrm{~mL} / \mathrm{s}$ while the device measures in real-time. However, the offline method is described as an alternative to the online method because NO is collected in a bag for later analysis using one of the following procedures: with a single exhalation maintaining a flow of $350 \mathrm{~mL} / \mathrm{s}$; breathing during constant flow against a pressure of $5 \mathrm{cmH}_{2} \mathrm{O}$, or breathing at tidal volume without the control of flow?

Unfortunately, asthma in children $<5$ years old is difficult to diagnose because symptoms are similar to those of other lung diseases ${ }^{6}$. Additionally, pulmonary function tests are difficult to perform correctly in this group of patients, considering that they have difficulties following the instructions to maintain the necessary constant flow for the correct measurement. Therefore, the best way to measure fractional exhaled nitric oxide (FENO) is to collect the exhaled air by breathing at tidal volume ${ }^{6,8}$. The standard way to measure FENO with the offline method at tidal volume is chemiluminescence technology. However, equipment with this technology is expensive and difficult to access. Although other devices with electrochemical technology are portable and easy to access, they are designed for online measurements ${ }^{9}$.

We hypothesize that the results of NO measurements collected at tidal volume can be similar, whether analyzed in chemiluminescence $\left({ }_{\mathrm{cl}}\right)$ or electrochemical $\left({ }_{\mathrm{eq}}\right)$ devices. Therefore, this study aimed to report the concordance and correlation of the results obtained by chemiluminescence vs. an electrochemical device using the offline technique collected at tidal volume in healthy children and children with lung disease.

\section{Methods}

A cross-sectional, observational, and prospective study was conducted in the Department of Respiratory Physiology of the National Institute of Respiratory Diseases (Instituto Nacional de Enfermedades Respiratorias, INER), Mexico City. It was approved by the Research and Bioethical Committee (agreement number $\mathrm{C} 14-19)$. Children between 1-11 years of age were invited to participate and recruited by a direct invitation from the institution's outpatient clinic or by relatives of hospitalized patients. Healthy individuals or children with any pulmonary disease were included. However, children who could not wear the mask due to facial malformations, those with chest, abdominal, oral, or facial pain, those with altered consciousness, and oxygen-dependent individuals were excluded from the study. Finally, those who fulfilled the inclusion criteria but could not tolerate breathing through the mask at tidal volume were also excluded.

We administered a respiratory health questionnaire and took anthropometric measurements, including weight $(\mathrm{kg})$ with a portable digital scale (Seca, model 813 and 232, Hamburg, Germany) and height (cm) with a mechanical stadiometer (Seca, model 206 and 232, Hamburg, Germany). Subsequently, the exhaled air sample for the evaluation of offline eNO at tidal 
volume was taken according to the recommendations of the ATS/ERS 2005 guidelines $^{7}$. The purpose and procedure of the test were explained to patients and family members. If the parents agreed to allow the child to participate, we proceeded with their signature in the consent letter.

\section{Calibration of the equipment}

We used the Sievers ${ }^{\circledR}$ 280i nitric oxide analyzer (General Electrics, Boulder, Colorado, USA), a high-sensitivity detector that measures exhaled nitric oxide based on gas-phase chemiluminescence $\left(\mathrm{eNO}_{\mathrm{cl}}\right)$ reaction between nitric oxide and ozone. The equipment has a vacuum pump, which provides a vacuum of $\sim 200 \mathrm{~mL} / \mathrm{min}$, that continuously extracts gas from the analyzer at a constant pressure. The limit for the measurement of nitric oxide in the gas phase is $\sim 0.5$ parts per billion (ppb), the sensitivity is $<1 \mathrm{ppb}$, with a range $<1-500,000 \mathrm{ppb}$, a response time of $67 \mathrm{~ms}$, and repeatability of $5 \%$.

The other equipment was the electrochemical $\left(\mathrm{eNO}_{\mathrm{eq}}\right)$ NO-Breath ${ }^{\circledR}$ (Bedfont, Harrietsham, England), which is based on an electrochemical sensor technology that reacts to the presence of nitric oxide. Its advantages are that it is portable, the detection range is $5-300 \mathrm{ppb}$, the repeatability is \pm 5 of a measured value $\leq 50 \mathrm{ppb}$ and \pm 10 of measured value $\geq 50 \mathrm{ppb}$, and the response is given in $<10 \mathrm{~s}$.

It is relevant to mention that the chemiluminescence equipment was calibrated daily by two methods. The first was zero gas calibration (NO $<1 \mathrm{ppb}$ ), achieved by placing a zero gas filter (which works by obtaining $\mathrm{NO}$ from the environmental air through a $\mathrm{KMnO}_{4^{-}}$ activated carbon filter to generate oxidation to $\mathrm{NO}_{2}$, which is absorbed by activated carbon) into the sampling line connection that goes to the equipment and opening the distal end to allow the flow. The filter is left connected for approximately $5 \mathrm{~min}$ to wash the sampling line of environmental air. Once the filter is placed, the device automatically calibrates to zero by measuring ppm at 0 and making a ppb adjustment with the calibration of the previous day. Calibration was also performed with a known gas concentration. For this procedure, a tank containing a gas between 10-100 ppb (usually $45 \mathrm{ppb}$ of $\mathrm{NO}$ in balance with $\mathrm{N}_{2}$ ) is connected to the sampling line where the analyzer provides a flow of $>200 \mathrm{~mL} / \mathrm{min}$ (generally at $300 \mathrm{~mL} / \mathrm{min}$ given by the regulator). After these steps, the flow is left for approximately $5 \mathrm{~min}$.

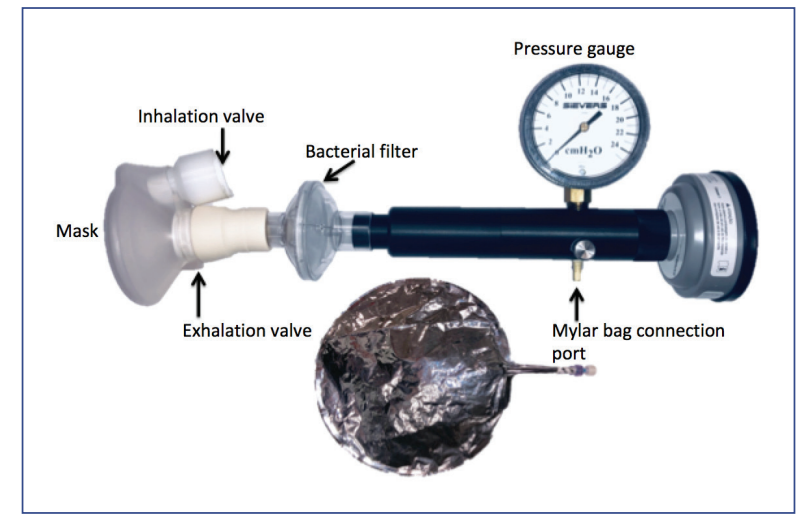

Figure 1. Mask with a unidirectional inhalation and an exhalation valve connected to a filter and a pressure measurement system.

Two or three calibrations should be performed to ensure repeatability. The response factor measured in ppm should be within a range of 0.09768 to 0.1465 , and the response factor in $\mathrm{ppb}$ should be within a range of 0.1953-0.293.

Conversely, electrochemical equipment is usually already calibrated according to the manufacturer's specifications. Therefore, it is only necessary to verify that the environmental module containing the equipment reads less than $5 \mathrm{ppb}$. Finally, the environmental reading in both instruments $<5 \mathrm{ppb}$ was verified before each measurement.

\section{Sample collection}

A mask with a unidirectional inhalation and exhalation valve, connected to a filter and pressure measurement system (Figure 1), was placed in patients seated with the back upright and the head slightly raised. At a tidal volume, patients were asked to breathe through the mask. Although the flow during the maneuver was not controlled, the pressure during breathing was monitored to stay above $5 \mathrm{cmH}_{2} \mathrm{O}$. In uncooperative children, we collected the sample at least with $2 \mathrm{cmH}_{2} \mathrm{O}$ of pressure. After three respiratory cycles were taken to wash the dead space of the system, the valve was changed to obtain the sample in the 1.5-liter Mylar ${ }^{\circledR}$ collection bag (Sievers Instruments, Boulder, Colorado, USA). We decided to stop the process once the patient had performed five breaths at a tidal volume or when the bag was filled at least half of its capacity. In the end, samples were analyzed in less than 48 hours following the ATS/ERS 2005 guidelines?. 


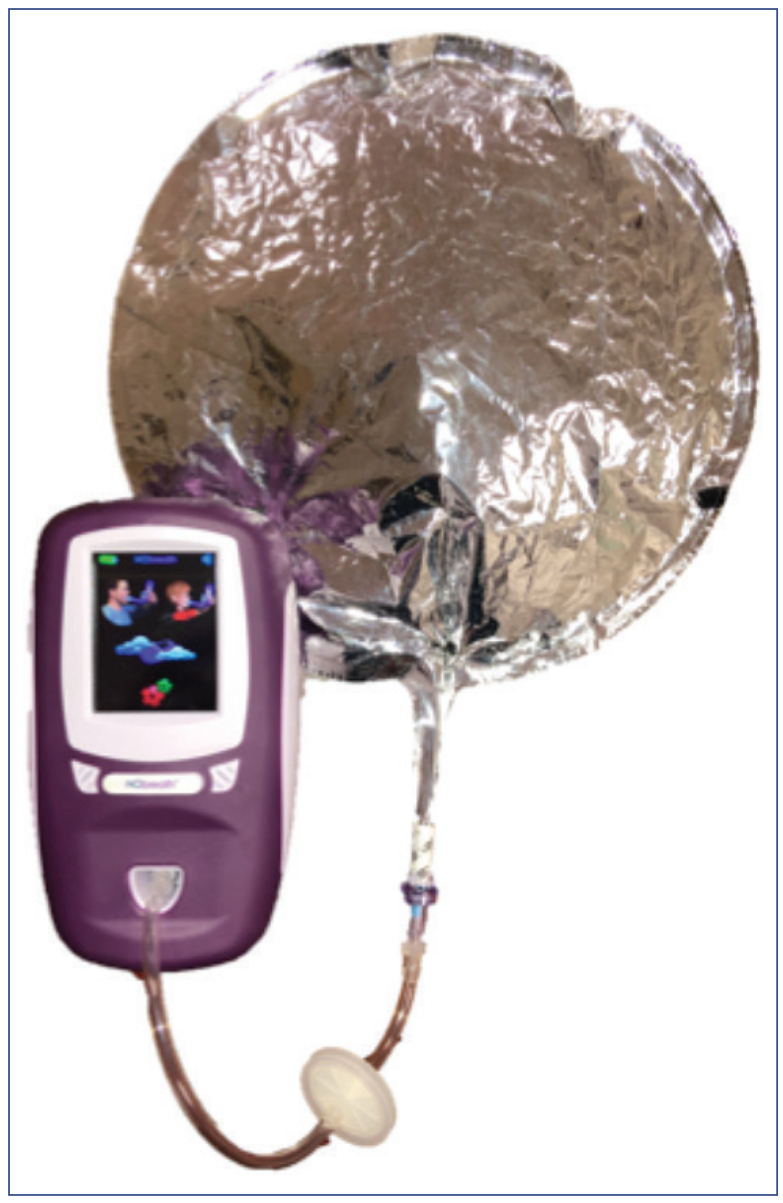

Figure 2. Mylarß bag connected to the sampling line and the electrochemical device.

\section{Sample analysis}

The analysis of the samples was carried out on both devices randomly. Regarding the chemiluminescence equipment, the sample was taken according to the manufacturer's recommendations: the Mylar ${ }^{\circledR}$ bag was connected to the sampling line (which has a vacuum pressure that makes a plateau with NO value during 5 to $10 \mathrm{~s})$. Subsequently, the measured values of NO were obtained. In the case of the electrochemical equipment, the Mylar ${ }^{\circledR}$ bag was connected to the device through a filter (Figure 2). Then, with the device in ambient mode, the suction pump was automatically activated, and after approximately $20 \mathrm{~s}$, the sample analysis was performed. Importantly, two measurements were taken in each device, ensuring a variability of less than $10 \%$, and the final result was formulated by the average of both measurements reported in $\mathrm{ppb}$. All the samples were analyzed in less than $120 \mathrm{~min}$.
Table 1. General characteristics of the participants

\begin{tabular}{|l|c|c|c|}
\hline & $\begin{array}{c}\text { Female } \\
(\mathbf{n}=12)\end{array}$ & $\begin{array}{c}\text { Male } \\
(\mathbf{n}=\mathbf{2 4})\end{array}$ & $\begin{array}{c}\text { Total } \\
(\mathbf{n}=\mathbf{3 6})\end{array}$ \\
\hline $\begin{array}{l}\text { Age } \\
\text { (years) }\end{array}$ & $6(4-8)$ & $6(5-8)$ & $6(5-8)$ \\
\hline $\begin{array}{l}\text { Weight } \\
(\mathrm{kg})\end{array}$ & $18.5(14.5-24)$ & $20(15-25.5)$ & $20(15-25)$ \\
\hline $\begin{array}{l}\text { Height } \\
(\mathrm{cm})\end{array}$ & $109(100.5-120.5)$ & $115(104-127.5)$ & $115(102-126)$ \\
\hline $\begin{array}{l}\text { eNO } \\
(\mathrm{ppb})\end{array}$ & $19.85(15.2-22.5)$ & $18.55(11.4-26.9)$ & $\begin{array}{c}19.15 \\
(12.2-26.2)\end{array}$ \\
\hline $\begin{array}{l}\text { eNO } \\
(\mathrm{ppb})\end{array}$ & $19(15.8-22.3)$ & $18(9.8-25)$ & $19(11.3-24)$ \\
\hline
\end{tabular}

Data are presented as median (percentile 25-75).

eNO ${ }_{c \prime}$ exhaled nitric oxide measured by the chemiluminescence device; $\mathrm{eNO}_{\mathrm{eq}}$ exhaled nitric oxide measured by the electrochemical device.

\section{Statistical analysis}

Descriptive statistics were expressed as the mean \pm standard deviation (SD) or median and interquartile range depending on the variables' distribution. Comparisons between both eNO devices were made using the paired Student's t-test. The correlation analysis was performed using the Spearman correlation coefficient (rsp), and the concordance correlation coefficient (CCC) was used to assess the degree of agreement between $\mathrm{eNO}_{\mathrm{cl}}$ and $\mathrm{eNO}_{\mathrm{eq}}$. Considering two measurements for each subject, an intraclass correlation coefficient of 0.8 , contrasted with an expected one of 0.5 , resulted in an alpha error of 0.05 , a power of 0.8 , and a $20 \%$ loss. Therefore, the required sample size was calculated to be 35 tests. A $p$-value $<0.05$ was defined to be significant, and a commercial statistical package was used to analyze the data (Stata V.13).

\section{Results}

A total of 36 children were studied, of which $24(67 \%)$ were male. The mean $( \pm S D)$ age of the study population was $6 \pm 2.6$ years old, with a minimum of 1 year and a maximum of 11 years; $9(25 \%)$ of the subjects were healthy, and the rest had a history of lung disease. The most frequent lung diseases were bronchopulmonary dysplasia (12; 33.3\%), asthma (11; 30.6\%), suspected primary ciliary dyskinesia (3; 8.3\%), and bronchiectasis not associated with cystic fibrosis $(1 ; 2.8 \%)$. Table 1 shows the general characteristics of the population. 


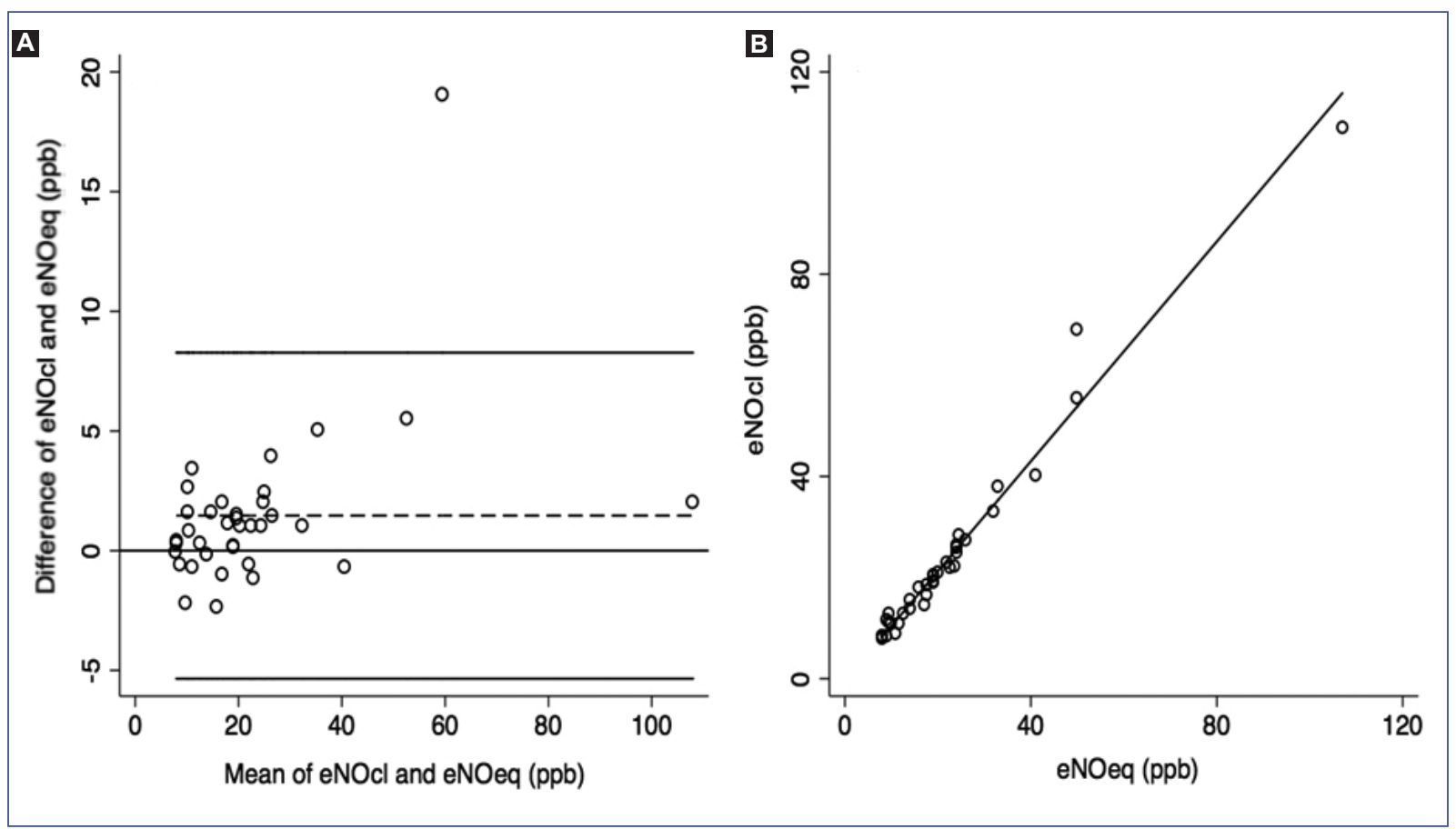

Figure 3. A: Bland-Altman graph showing the agreement between both devices, the Sievers ${ }^{\circledR}\left(\mathrm{eNO}_{\mathrm{cl}}\right)$ and the Bedfont ${ }^{\circledR}$ $\left(\mathrm{eNO}{ }_{\mathrm{eq}}\right)$. CCC $=0.98$. B: Spearman correlation between both devices $(\mathrm{rsp}=0.98)$.

$\mathrm{eNO}_{\mathrm{c}}{ }^{\mathrm{eq}}$ exhaled nitric oxide measured by the chemiluminescence device; $\mathrm{eNO}_{\mathrm{eq}}$, exhaled nitric oxide measured by the electrochemical device.

The CCC between the two measuring devices was 0.98 , with an average difference of $1.46 \pm 3.5 \mathrm{ppb}$ and $95 \%$ limits of agreement from $-5.3 \mathrm{ppb}$ to $8.3 \mathrm{ppb}$. The Bland-Altman graphs are shown in Figure 3: the agreement between the two measuring devices (Figure $3 \mathrm{~A}$ ) and the Spearman's correlation coefficient $(r=0.98$; $p<0.001$ ) (Figure 3B) The linear regression model equation for eNO estimation was $\mathrm{eNO}_{\mathrm{cl}}=\left(\mathrm{eNO}_{\mathrm{eq}} \cdot 1.0718\right)$ $-0.1343\left(r^{2}=0.97\right)$. We decided to categorize the subjects into groups to see the concordance between the categories with eosinophilic inflammation. The CCC between devices was 0.92 in the $<20$ ppb group, 0.89 in the 20-35 ppb group, and 0.94 in the group with $>35 \mathrm{ppb}$ (Table 2).

\section{Discussion}

This study demonstrates that the eNO results obtained by chemiluminescence and electrochemical equipment, using the offline method and the tidal volume technique, are interchangeable. We also described the technique to analyze the samples using electrochemical equipment, which is more accessible and inexpensive.
Table 2. Concordance by category according to FENO values in children

\begin{tabular}{|l|c|c|c|}
\hline & $\begin{array}{c}\text { FENO } \leq \mathbf{2 0}^{*} \\
(\mathbf{n}=\mathbf{1 9})\end{array}$ & $\begin{array}{c}\text { FENO } \\
\mathbf{2 0 *} \\
(\mathbf{n}=\mathbf{1 2})\end{array}$ & $\begin{array}{c}\text { FENO } \\
\mathbf{>} \text { 35* } \\
\mathbf{( n = 5 )}\end{array}$ \\
\hline CCC & 0.92 & 0.89 & 0.94 \\
\hline Mean difference \pm SD & $-0.38 \pm 1.5$ & $-1.5 \pm 1.6$ & $-6.1 \pm 7.6$ \\
\hline$r$ & 0.93 & 0.96 & 0.96 \\
\hline Limits of agreement & -3.3 to 2.5 & -4.7 to 1.7 & -2.1 to 8.7 \\
\hline
\end{tabular}

${ }^{*} p<0.001$.

CCC, concordance correlation coefficient; FENO, fractional exhaled nitric oxide; $\mathrm{SD}$, standard deviation.

Asthma is the most frequent chronic disease in children, and its prevalence is higher in children under the age of 5 years ${ }^{10}$. In these cases, asthma manifestations depend on the interaction between genetic and environmental factors, and it differs from person to person according to their phenotype, genotype, and endotype ${ }^{4,6}$. Asthma continues to cause high morbidity and mortality worldwide, mainly due to the absence of suspicion and difficulty making the diagnosis. This difficulty is evident 
in preschoolers because of their lack of cooperation to undergo a respiratory function test. Consequently, the diagnosis is based mainly on predictive indices in which pulmonary function and the degree of inflammation in the respiratory tract are not considered ${ }^{3}$.

In 2001, the ATS/ERS published the clinical guidelines for interpreting eNO measurements in adults and children, establishing cutoff points to define when inhaled steroid treatment should be administered and when it should be increased or decreased ${ }^{5}$. However, these guidelines and other studies considered only patients $>4$ years of age, and the method used was the online method, where the individual must maintain a flow of $50 \mathrm{~mL} / \mathrm{s}^{11-16}$. In 2005, the ATS/ERS made some recommendations for the standardization of measurements of eNO with the online and offline methods, and the offline measurement of eNO at tidal volume is mentioned as an alternative to the other methods described?

By the end of the 1990s, some studies were published concerning toddlers and preschoolers with wheezing in whom eNO was measured with the offline method at tidal volume using chemiluminescence equipment. It was shown that preschoolers presented higher values of eNO during wheezing episodes (14.1 $\pm 1.8 \mathrm{ppb}$ ), which improved after steroid treatment, reducing eNO levels up to $52 \%{ }^{17}$. Additionally, it was shown that exhaled air could be easily collected from these children, allowing to differentiate among asthmatic patients, those with chronic non-asthmatic cough, and healthy children ${ }^{8,18}$. As a result, these authors concluded that the offline method is easy to perform and can be executed on an outpatient basis ${ }^{17,18}$. Similar to these results, we demonstrated that the sample was easy to obtain without causing any discomfort to the children.

Moreover, several studies have reported reference values with the offline method at different respiratory flows, even in children $<2$ years of age a $^{9,12,13,16,19-22}$. However, the main limitation to reproduce this technique is the availability of chemiluminescence equipment, which is expensive and difficult to access for most centers ${ }^{23}$. The present study demonstrates that the measurements of eNO obtained by the offline technique through breathing at tidal volume can be analyzed by electrochemical devices, and the results are interchangeable with those analyzed using the gold standard chemiluminescence equipment. This interchangeability is established based on the high concordance and correlation coefficients (CCC $=0.98$, $r s p=0.97, p<0.001$ ), and it is important for the pediatric population because the offline method can be used in uncooperative patients. Also, we categorized to find the CCC between groups (probable eosinophilic inflammation) and obtained a value of 0.92 in $<20 \mathrm{ppb}$, 0.89 in 20-35 ppb, and $0.94>35 \mathrm{ppb}$; thus, both methods could identify low and high values of eNO. Equally important, using portable equipment that exists in the market could expand the spectrum of use in the clinical setting and as a good alternative for conducting epidemiological studies on a larger scale. Like other authors ${ }^{9,17,20,22}$, we used the bags recommended by the chemiluminescence equipment manufacturer $\left(\mathrm{Mylar}^{\circledR}\right.$ bag) in this study, which are the typical bags made of a stretched polyester film (biaxial-oriented polyethylene terephthalate) that come with a connector and a unidirectional valve that facilitate obtaining the sample. In addition, these bags' material is the same as that used for balloons, and we consider that if it is used with another type of adapter, the cost for every measure could decrease considerably?.

Although our main objective in this study was to evaluate the agreement in exhaled nitric oxide measured offline at a tidal volume between the two devices, these results should be corroborated in patients with different clinical spectrum (e.g., patients with diseases or conditions that decrease nitric oxide and patients with very high values of it) to be used in clinical practice. A limitation of this study was that we did not control the flow, although our method can be used in noncooperative children, and additionally, the main objective was to validate interchangeability between devices.

In conclusion, the measurement of eNO by the offline method can be analyzed in an electrochemical device, and the results are interchangeable with those obtained in chemiluminescence equipment.

\section{Ethical disclosures}

Protection of human and animal subjects. The authors declare that no experiments were performed on humans or animals for this study.

Confidentiality of data. The authors declare that they have followed the protocols of their work center on patient data publication.

Right to privacy and informed consent. The authors have obtained the written informed consent of the patients or subjects mentioned in the article. The corresponding author has this document.

\section{Conflicts of interest}

The authors declare no conflict of interest. 


\section{Funding}

None.

\section{References}

1. Palmer RM, Ferrige AG, Moncada S. Nitric oxide release accounts for the biological activity of endothelium-derived relaxing factor. Nature 1987;327:524-6.

2. Gustafsson LE, Leone AM, Persson MG, Wiklund NP, Moncada S. Endogenous nitric oxide is present in exhaled air of rabbits, guinea pigs and humans. Biochem Biophys Res Commun. 1991;181:853-7.

3. Cantú-González G, Fernández-Figueroa F, Gochicoa-Rangel L, Miguel-Reyes JL, Vargas-Domínguez C, Mejía-Alfaro R, et al. Fracción exhalada de óxido nítrico. Recomendaciones clínicas y procedimiento. Neumol Cir Torax. 2013;72:43-51.

4. Global strategy for asthma management and prevention. Fontana, WI: Global Initiative for Asthma; 2019. Available at: https://ginasthma.org.

5. Dweik RA, Boggs PB, Erzurum SC, Irvin GC, Leigh MW, Lundberg JO, et al. An official ATS clinical practice guideline: interpretation of exhaled nitric oxide levels (FENO) for clinical applications. Am J Respir Crit Care Med. 2011;184:602-15.

6. Larenas-Linnemann D, Salas-Hernández J, Vázquez-García JC, Ortiz Al, Fernández VM, del Río NBE, et al. Guía Mexicana del Asma 2017. Neumol Cir Torax. 2017;76:1-137.

7. American Thoracic Society; European Respiratory Society. ATS/ERS recommendations for standardized procedures for the online and offline measurement of exhaled lower respiratory nitric oxide and nasal nitric oxide, 2005. Am J Respir Crit Care Med. 2005;171:912-30.

8. Canady RG, Platts-Mills T, Murphy A, Johannesen R, Gaston B. Vital capacity reservoir and online measurement of childhood nitrosopnea are linearly related. Am J Respir Crit Care Med. 1999;159:311-4.

9. van der Heijden HHACM, Brouwer ML, Hoekstra F, van-der-Pol P Merkus PJFM. Reference values of exhaled nitric oxide in healthy children 1-5 years using offline tidal breathing. Pediatr Pulmonol. 2014;49:291-5.

10. Lai CKW, Beasley R, Crane J, Foliaki S, Shah J, Weiland S; Internationa Study of Asthma and Allergies in Childhood Phase Three Study Group. Global variation in the prevalence and severity of asthma symptoms: phase three of the International Study of Asthma and Allergies in Childhood (ISAAC). Thorax 2009;64:476-83.
11. Buchvald F, Baraldi E, Carraro S, Gaston B, De Jongste J, Pijnenburg MWH, et al. Measurements of exhaled nitric oxide in healthy subjects age 4 to 17. J Allergy Clin Immunol. 2005;115:1130-6.

12. Baraldi E, Azzolin NM, Cracco A, Zacchello F. Reference values of exhaled nitric oxide for healthy children 6-15 years old. Pediatr Pulmonol. 1999;27:54-8.

13. Wong GW, Liu EK, Leung TF, Yung E, Ko FWS, Hui DSC, et al. High levels and gender difference of exhaled nitric oxide in Chinese schoolchildren. Clin Exp Allergy. 2005;35:889-93.

14. Olivieri M, Talamini G, Corradi M, Perbellini L, Mutti A, Tantucci C, et al. Reference values for exhaled nitric oxide study (reveno) study. Respir Res. 2006;7:94.

15. Travers J, Marsh S, Aldington S, Williams M, Shirtcliffe P, Pritchard $A$, et al. Reference ranges for exhaled nitric oxide derived from a random community survey of adults. Am J Respir Crit Care Med. 2007; 176:238-42.

16. Menou A, Babeanu D, Paruit HN, Ordureau A, Guillard S, Chambellan A. Normal values of offline exhaled and nasal nitric oxide in healthy children and teens using chemiluminescence. J Breath Res. 2017;11:036008.

17. Baraldi E, Dario C, Ongaro R, Scollo M, Azzolin NM, Panza N, et al. Exhaled nitric oxide concentrations during treatment of wheezing exacerbation in infants and young children. Am J Respir Crit Care Med. 1999:159:1284-8.

18. Avital A, Uwyyed K, Berkman N, Godfrey S, Bar-Yishay E, Springer C. Exhaled nitric oxide and asthma in young children. Pediatr Pulmonol. 2001;32:308-13.

19. Gabriele C, Nieuwhof EM, Van Der Wiel EC, Hofhuis W, Moll HA, Merkus PJFM, et al. Exhaled nitric oxide differentiates airway diseases in the first two years of life. Pediatr Res. 2006;60:461-5.

20. Meyts I, Proesmans M, Gerven VV, Hoppenbrouwers K, De Boeck K. Tidal offline exhaled nitric oxide measurements in a pre-school population. Eur J Pediatr. 2003;162:506-10.

21. Wildhaber JH, Hall GL, Stick S. Measurements of exhaled nitric oxide with the single-breath technique and positive expiratory pressure in infants. Am J Respir Crit Care Med. 1999;159:74-8.

22. Daniel PF, Klug B, Valerius $\mathrm{NH}$. Exhaled nitric oxide in healthy young children during tidal breathing through a facemask. Pediatr Allergy Immunol. 2007;18:42-6.

23. Kim SH, Moon JY, Kwak HJ, Kim SI, Park DW, Kim JW et al Comparison of two exhaled nitric oxide analyzers: the NIOX MINO hand-held electrochemical analyzer and the NOA280i stationary chemiluminescence analyzer. Respirology. 2012;17:830-4. 